\title{
Competitive employment for consumers who are legally blind: A 10-year retrospective study
}

\author{
Edward Bell, PhD, CRC, NOMC \\ Professional Development and Research Institute on Blindness, Louisiana Tech University, Ruston, LA
}

\begin{abstract}
Vocational rehabilitation consumers who are legally blind are a subgroup of the larger population of individuals with disabilities who have suffered high rates of unemployment; yet, the evaluation standards and performance indicators of the Rehabilitation Services Administration (RSA) show that each year, the rates of employment for individuals with disabilities continue to increase overall. The question being investigated is, Has the employment rate similarly increased for this subgroup of consumers? Using the RSA-911 data system, this study investigated the competitive employment rates for consumers who are legally blind over a 10-year period spanning fiscal years 1997 to 2007. This study also compares differences in wages for consumers who were employed when they applied for services versus when they retained or advanced in employment at case closures. Results show that rates of employment and wages have steadily increased for consumers who are legally blind over the period of analysis.
\end{abstract}

Key words: competitive closure rate, competitive employment, employment characteristics, employment closures, employment trends, legally blind consumers, race, RSA-911, sex, vocational rehabilitation, wages.

\section{INTRODUCTION}

The U.S. Department of Education maintains the Rehabilitation Services Administration (RSA)-911 reporting system, which captures data on consumers of vocational rehabilitation (VR) throughout the life of their cases.
Researchers have investigated data captured in the RSA911 data system for a number of years to examine employment characteristics of individuals with disabilities. These data have been the focus of a number of research studies that have investigated the competitive closure rates (CCRs) for consumers who are blind [1-3]; yet, confusion still remains as to what the employment prospects are for individuals who are legally blind. Using the RSA-911 data system, this study examined a 10-year trend of employment characteristics for VR consumers who had a primary diagnosis of legal blindness.

Previous outcome research has investigated the VR system and predictive factors such as consumer personal/ work history [1,4-6], the quality of the VR counselor [7$10]$, and the overall State-Federal VR system $[1,11]$.

Although RSA recognized six categories of employment status before fiscal year (FY) 2002 (i.e., employment without supports in integrated settings, extended employment, self-employment, State agency-managed Business

\footnotetext{
Abbreviations: $\mathrm{BEP}=$ Business Enterprise Program, $\mathrm{CCR}=$ competitive closure rate, FY = fiscal year, RSA = Rehabilitation Services Administration, $\mathrm{SD}=$ standard deviation, $\mathrm{VR}=$ vocational rehabilitation.

Address all correspondence to Edward Bell, PhD, CRC, NOMC; Professional Development and Research Institute on Blindness, Louisiana Tech University, PO Box 3158, 210 Woodard Hall, 100 Wisteria, Ruston, LA 71272; 318-2574554; fax: 318-257-2259. Email: mailto:ebell@latech.edu DOI:10.1682/JRRD.2009.08.0120
} 
Enterprise Program [BEP], homemaker, and unpaid family worker) within the status 26 employment, ${ }^{*}$ most research in the VR field has focused on competitive closures. RSA has established competitive employment as the mission of rehabilitation services as it has been articulated in the amendments to the Rehabilitation Act of 1973 in 1992 and 1998. The Commissioner of RSA reiterated this priority when describing the changing patterns in the VR system. Schroeder reported that consumers who were placed in competitive integrated employment made rapid gains in earnings and access to insurance [12]. Over a 3-year period, competitively employed consumers increased their wages on average from \$7.56 to \$13.24 an hour. Within this same time frame, the availability of medical insurance through work for these consumers increased from 38 to 58 percent, which is close to the national average of 64.5 percent [12].

Although the research into closure rates for individuals who are legally blind has been quite sparse in the literature [1-2], evidence demonstrates a trend of stagnation, with relatively low rates of competitive employment outcomes. According to the RSA, three categories of competitive employment exist for consumers who are legally blind, including (1) competitive, which are found in mainstream integrated settings; (2) BEP, which is a State-managed vending program under the RandolphSheppard Act; and (3) self-employment, where the individual demonstrates wages earned for entrepreneurial pursuits. Hill investigated the work status outcomes of consumers who were legally blind in 1982 [5]. The report revealed that of $>18,000$ clients served who were visually impaired and legally blind, 8,939 men and women (48.6\%) were placed in competitive employment. The competitive employment finding is similar to the findings of Kirchner and Schmeidler [13]. They reported that clients who were visually impaired and legally blind were competitively employed at a rate of 57 percent, whereas other individuals with disabilities were competitively employed at a rate of 81 percent when their VR cases were closed [13]. More than a decade later, Cavenaugh demonstrated that these low rates of employment for

\footnotetext{
*RSA recognizes some 38 different "statuses" in all. Because RSA relates to the case closure and therefore the RSA-911 data system, about six statuses are relevant, only two of which are relevant to this article. Status 26 refers to consumers who became employed and includes the six categories listed here. Status 28 refers to all the individuals who received VR services but were unable to obtain a job. Statuses 08, 30, and 38 refer to individuals who applied but never received VR services.
}

individuals who were legally blind have continued to stagnate or deteriorate [1]. Specifically, Cavenaugh reported that of more than 18,000 consumers who are legally blind whose cases were closed in FY 1995, only 25.1 percent were employed in competitive, BEP, or selfemployment, while 43.5 percent were closed in extended employment, homemaker, or unpaid family worker statuses. Additionally, another 31.4 percent of these cases were closed unsuccessfully (i.e., without an employment outcome).

A number of indexes have been used over the years for measuring the effectiveness of the VR system. Among the factors evaluated, the consumer's ability to obtain employment with earnings at or above the minimum wage has remained a popular measure. The CCR was first presented as a measure of VR counselor effectiveness by Szymanski and Parker [9] and has been applied to the study of VR counselor effectiveness in a number of subsequent studies [7-8,14].

Szymanski and Parker conducted a comprehensive review of the rehabilitation literature and identified competitive employment (work for wages or salary at or above the Federal minimum wage) and the severity of disability as two important factors affecting employment outcomes [9]. From this information, they created CCR and defined it as the rate of all consumers closed in the Status 26 category (competitive employment) to the rate of all other case closures, including noncompetitive Status 26 closures, such as homemaker, extended employment, and unpaid family worker. CCR is the rate of competitive employment closures divided by all other case closures. This divisor includes individuals who obtained an employment outcome in a noncompetitive setting (extended employment, homemaker, or unpaid family worker), received rehabilitation services under a plan for employment but did not obtain employment (Status 28), and applied for services and may have received assessment and diagnosis services but never developed a plan for employment (Statuses 08, 30, and 38, respectively). Even though these latter three categories did not receive services toward attaining a vocation, including them within the index is justified since caseload dollars are spent and counselor time is invested in the processing of these cases.

Understanding how the CCR variable is constructed is important because similar measures may yield considerably different results. The RSA, for example, also calculates the percentage of consumers who obtained an employment outcome; however, the formula used by RSA 
is quite different from the CCR variable as defined by Szymanski and Parker [9]. During the calculation of employment closures for the standards and indicators reports, RSA only considers cases in which a plan for employment was carried out (closure Statuses 26 and 28). Consequently, all cases that were closed because the individual was ineligible (Status 08) or was determined eligible but never served (Statuses 30 and 38) are not considered in the formula. Also, this approach to measurement is sufficiently justified, since one can argue that the VR system should only be measured based on those individuals who were active participants in the VR process (Statuses 26 and 28).

This study focused on CCR because it is believed to be a more comprehensive measure of VR effectiveness, and it may draw more meaningful conclusions with existing published studies. For consumers who are legally blind, BEP (or vending under the Randolph-Sheppard Act) and self-employment are considered within the competitive employment category and are consequently included in the CCR variable [2-3].

\section{METHODS}

\section{Participants}

The target population for this study was all consumers who exited the State-Federal VR system during FYs 1997 to 2007 and who had a primary disability diagnosis of legal blindness $(N=188,978)$. The proportion of participants was equivalently distributed across the 11 FYs. This study did not include consumers who reported their secondary disability as blindness; however, because of the concomitant nature of many disabilities, consumers were not excluded who reported the presence of secondary disabilities.

Across this 10-year span (1997-2007), the sex representation of the sample was 89,204 males (47.20\%) and 99,759 females (52.79\%). Sex representation steadily shifted over this period, where in FY 1997, males represented 45 percent and females 55 percent, and by FY 2007, males represented 52 percent and females were 48 percent; males became $>50$ percent of the population for the first time in FY 2006. The mean age of consumers \pm standard deviation (SD) over this time span was $48.13 \pm$ 19.86 years, ranging from a minimum of 14 years to a maximum of 104 . The average age remained stable across the $10 \mathrm{FYs}$.

\section{Procedures}

I obtained annual case closure data for all 50 states through the RSA within the Office of Special Education and Rehabilitative Services under the U.S. Department of Education. These data are the annual case closure information reported in the RSA-911 data system for all consumers of VR services in the United States each year. Consumerlevel data were aggregated for each FY from 1997 to 2007. In FY 2002, the RSA-911 data system changed significantly. Consequently, considerable data were recoded for merging and matching the data sets from 1997 to 2001 with the newer system that took effect for FYs 2002 to 2007.

\section{Instrumentation}

This study used the RSA-911 data system for all analyses. The primary variable investigated was CCR. Szymanski and Parker calculated the competitive closure variable by averaging the number of consumers with a competitive work status divided by those with noncompetitive and unemployed closure statuses [9]. For the target population, this study included self-employment and State-agencymanaged business (BEP) (or vending facility) closures; hence, the CCR variable includes all competitive, selfemployment, BEP, and extended employment closures as a ratio with all other case closures.

One other variable explanation should be noted. The goal of VR services is to help individuals with disabilities become employed; however, the mission of RSA is to help individuals with disabilities obtain, retain, or advance in employment. Consequently, individuals in the VR system who are already working often apply for VR services to help them retain their current job and/or obtain training to advance in employment. This study seeks to include both populations of consumers; however, sorting out the population who is finding work for the first time versus those who are seeking to retain/ advance in employment is important.

To understand the employment trends of VR consumers, I created four additional variables to examine the employment status of consumers from the time they entered the VR system to the time they left. To create them, I combined the employment status recorded at the time of application along with the employment status at closure. The variables included those persons who-

- Were unemployed at application and remained unemployed at closure.

- Lost employment or were employed at the time of application but were unemployed at closure. 
- Retained employment, i.e., were employed at application and remained so at closure.

- With VR employment, were unemployed at application but became employed by case closure.

\section{RESULTS}

Based on the CCR from FYs 1997 to 2007, VR consumers who were legally blind had an average employment rate of 31.79 percent. This percentage is considerably higher than the 25.1 percent that Cavenaugh reported that was based on data from FY 1995 [1]. In fact, the CCR has demonstrated a steady climb from 27 percent in 1997 up to a high of 37 percent in 2007. This difference is more than an 11 percent increase in the rate of employment for the target population in just over a decade. While this trend is quite promising, a concern is that the overall number of consumers closed decreased during this same time from 18,596 in FY 1997 down to 14,276 in FY 2007. Table 1 contains the CCRs for all FYs 1997 to 2007.

I also examined the rate of employment to unemployment and wages for consumers who were legally blind with respect to any sex differences. One should note, however, that because of the very large sample size $(187,000)$, virtually any difference would appear as statistically significant, even if no meaningful differences exist. Consequently, mean values \pm SD and percentages rather than significance testing

Table 1.

Competitive closure rate (CCR) for consumers who were legally blind ( $N=188,978)$, fiscal years (FYs) 1997-2007.

\begin{tabular}{|c|c|c|c|c|}
\hline FY & $n^{*}$ & $\operatorname{CCR}(\mathrm{A})(\%)^{\dagger}$ & $\operatorname{CCR}(\%)^{\ddagger}$ & Diff $(\%)^{\S}$ \\
\hline 1997 & 18,596 & 21.00 & 27.04 & 6.04 \\
\hline 1998 & 18,503 & 22.13 & 27.91 & 5.78 \\
\hline 1999 & 18,976 & 23.69 & 29.51 & 5.82 \\
\hline 2000 & 19,465 & 25.62 & 31.62 & 6.00 \\
\hline 2001 & 19,057 & 26.57 & 31.86 & 5.29 \\
\hline 2002 & 17,572 & 22.51 & 33.49 & 10.98 \\
\hline 2003 & 17,363 & 21.53 & 31.72 & 10.19 \\
\hline 2004 & 15,776 & 21.63 & 32.44 & 10.81 \\
\hline 2005 & 15,226 & 22.25 & 33.61 & 11.36 \\
\hline 2006 & 14,168 & 23.36 & 35.59 & 12.23 \\
\hline 2007 & 14,276 & 22.92 & 37.16 & 14.24 \\
\hline \multicolumn{5}{|c|}{$\begin{array}{l}{ }^{*} \text { Total number of closed cases with employment outcome. } \\
{ }^{\dagger} \text { Rate proportion of consumers who held a job at time of application (A). } \\
\text { †Rate for consumers who were legally blind at case closure. } \\
\text { § } 2 \text { Difference (Diff) between consumers employed at application vs closure. }\end{array}$} \\
\hline
\end{tabular}

are presented. With respect to sex, 8,269 men obtained a competitive employment outcome, or $34.20 \pm 0.47$ percent, as compared with 10,235 women who obtained a competitive employment rate of $21.30 \pm 0.41$ percent. Ten years later, the rates had begun to level off, when men were employed $39.00 \pm 0.48$ percent of the time, as compared with women who were employed $35.00 \pm 0.47$ percent of the time. The data demonstrated that the average hourly wage for men who were employed in 1997 was $\$ 9.02 \pm$ $\$ 6.01$, as compared with women whose average hourly wage was $\$ 8.39 \pm \$ 6.03$. Ten years later, men were earning an average hourly wage was $\$ 13.58 \pm \$ 11.98$ as compared with women whose hourly wage was $\$ 12.72 \pm \$ 8.79$.

I examined the same data to identify differences that may exist by race. The rate of employment to unemployment for consumers who are legally blind was relatively consistent across racial groups. In 1997, the rate of competitive employment for each racial group employed was 27 percent for White/Anglo American; 24 percent, Black/ African American; 22 percent, Native American; 32 percent, Asian/Pacific Islander; and 28 percent, Hispanic. I compared these data with the same groups employed in 2007: 39 percent, White/Anglo American; 31 percent, Black/African American; 25 percent, Native American; 36 percent, Asian/Pacific Islander; and 39 percent, Hispanic. When I examined the hourly wage, a similar trend emerged. In 1997, the hourly earning averages were \$9.09 for White/Anglo American; \$7.73, Black/African American; \$8.10, Native American; \$11.84, Asian/ Pacific Islander; and \$7.49, Hispanic. By 2007, over the 10 -year time span, these earning averages had increased to \$13.56 for White/Anglo American; \$11.58, Black/ African American; \$12.14, Native American; \$14.28, Asian/Pacific Islander, and \$12.99, Hispanic.

The level of education that consumers had achieved by case closure was also an important variable in examining employment outcomes. This education level was not available for consumers during FYs 1997 to 2001; consequently, this part of the analysis involves only data from FYs 2002 to 2007. During FY 2007, approximately 17 percent of consumers who were legally blind had less than a high school diploma; the majority, 51 percent, had a high school diploma; 10 percent had an associate's degree; 13 percent had a bachelor's degree; and 7.19 percent had a master's degree or higher. The data from 2007 showed that consumers who were legally blind with-

- Less than a high school diploma, 23 percent had obtained an employment outcome. 
- A high school diploma, 32 percent had obtained an employment outcome.

- An associate's degree, 47 percent were employed.

- A bachelor's degree, 55 percent were employed.

- A master's degree or higher, 61 percent were employed These data were relatively stable in FY 2002, so only the 2007 data are presented here. Also, during FY 2007, individuals who were legally blind with-

- Less than a high school diploma earned an average of $\$ 9.62$ an hour.

- A high school diploma earned \$10.97.

- An associate’s degree earned \$12.69.

- A bachelor’s degree earned \$15.36.

- A master's or higher earned \$21.86.

Data were also examined for veterans of the U.S. Armed Forces. Although the Department of Veterans Affairs has primary responsibility for providing rehabilitation services to veterans, many veterans receive training through civilian VR programs. Data were only available specifically to veterans between FYs 2002 and 2007. During this time, 525 veterans who were legally blind exited the VR program. Their mean age was $58.00 \pm 16.27$, 444 were male (84.6\%), and 82 were female (15.6\%). These individuals exited with an employment outcome about 18 percent of the time, earning \$10.58 an hour.

While this steady increase in employment is encouraging, Bell reported a concerning trend of concurrent increases in the relative proportion of consumers entering the VR process who were already employed [3]. The mission of VR is to help consumers obtain, retain, or advance in employment, so logically, individuals would apply for services even though they are already employed. Nevertheless, concerns have been raised over whether closure data were misleading from state to state based on the proportion of consumers who were already employed (i.e., VR counselors receive the same credit for a competitive employment closure whether VR placed the person in employment or whether the person was already employed when receiving services). Bell revealed that while some State agencies closed a considerably higher proportion of consumers with blindness in competitive employment than other agencies, these same agencies also had a significantly higher proportion of consumers with blindness already employed when they applied for services [3]. In the current study, the data demonstrated that 21 percent of consumers with blindness were employed when they applied for services in 1997. A trend of increasing numbers of already-employed consumers applying for services until FY 2001 showed that 26.5 percent of consum- ers were already employed; however, this trend decreased and remained relatively stable from FYs 2002 to 2007. The rate of employment for consumers at application, along with the difference in closure rate, can be found in Table $\mathbf{1}$.

To better understand the employment trends for this population (as I mentioned earlier), I created four variables to examine the proportion of consumers who were (1) unemployed at application and remained unemployed at closure; (2) lost employment or were employed at the time of application but were unemployed at closure; (3) stagnation retained employment, i.e., were employed at application and remained so at closure; or (4) with VR employment, were unemployed at application but became employed by case closure. The data demonstrated that 61 percent of consumers who came to the VR process unemployed exited the system without obtaining an employment outcome. This rate remained relatively stable across the 10-year period of this study. An additional 6.8 percent of consumers applied for services while possessing a competitive job, but lost this job, or otherwise were unemployed by the time their cases closed. An average of 16.19 percent of consumers retained or advanced in their employment. As previously noted, this rate of employment was an increasing trend that began at 13 percent in FY 1997, peaked at 17.8 percent in FY 2001, and remained at a somewhat high 17.2 percent by FY 2007. Of course, individuals who are employed because of the VR process are of the most interest in examining VR. This study demonstrated that an average of 15.8 percent of consumers became employed during the process during this time and that this trend had been increasing from a low 13.5 percent in FY 1997 to a high 19.9 percent in FY 2007. These data are reported for the 11 FYs in Table 2.

Because the trend has demonstrated increasing competitive employment closures for this population over the decade, determining whether wages have correspondingly increased over this same period is also important. In the RSA-911 data system, wages are captured as total weekly dollars for the consumer, divided by the minimum hourly wage in the consumer's state, which is how the wage rate is calculated for the evaluation standards and performance indicators [15]. In the current study, I report the raw weekly wages. The data demonstrate that average weekly wages of consumers who are legally blind increased from \$293.08 in FY 1997 to \$421.06 in FY 2007, an average increase of $\$ 127.98$ a week (Table 3). As previously noted, consumers during this time were also employed at the time of application in increasingly higher numbers. As 
Table 2.

Employment matrix for consumers who were legally blind $(N=$ 188,978), fiscal years (FYs) 1997-2007.

\begin{tabular}{|c|c|c|c|c|c|}
\hline FY & $\begin{array}{l}\text { None* }^{*} \\
(\%)\end{array}$ & $\begin{array}{l}\text { Lost Emp }{ }^{\dagger} \\
\quad(\%)\end{array}$ & $\begin{array}{l}\text { Alr Emp } \operatorname{Em}^{\ddagger} \\
\quad(\%)\end{array}$ & $\begin{array}{l}\text { VR Emp } \operatorname{Em}^{\S} \\
(\%)\end{array}$ & $n^{9}$ \\
\hline 1997 & 65.48 & 7.48 & 13.52 & 13.52 & 18,596 \\
\hline 1998 & 64.19 & 7.90 & 14.23 & 13.68 & 503 \\
\hline 1999 & 62.52 & 7.97 & 15.71 & 13.80 & 18,976 \\
\hline 2000 & 59.76 & 8.62 & 17.00 & 14.62 & 19,465 \\
\hline 2001 & 59.45 & 8.70 & 17.87 & 13.98 & 19,057 \\
\hline 2002 & 61.22 & 5.30 & 17.22 & 16.26 & 17,572 \\
\hline 2003 & 62.90 & 5.38 & 16.15 & 15.57 & 17,363 \\
\hline 2004 & 61.83 & 5.73 & 15.90 & 16.54 & 15,776 \\
\hline 2005 & 60.42 & 5.96 & 16.28 & 17.34 & 15,226 \\
\hline 2006 & 58.12 & 6.30 & 17.06 & 18.52 & 14,168 \\
\hline 2007 & 57.12 & 5.72 & 17.20 & 19.96 & 14,276 \\
\hline$\overline{\text { Mean }}$ & 61.18 & 6.82 & 16.19 & 15.80 & - \\
\hline \multicolumn{6}{|c|}{$\begin{array}{l}\text { *Proportion of consumers who were unemployed at application and remained } \\
\text { employed at case closure. }\end{array}$} \\
\hline \multicolumn{6}{|c|}{$\begin{array}{l}{ }^{\dagger} \text { Consumers who were employed at application but were closed without } \\
\text { employment. }\end{array}$} \\
\hline \multicolumn{6}{|c|}{$\begin{array}{l}\text { ҒConsumers who were already employed (Alr Emp) at application and } \\
\text { remained employed at closure. }\end{array}$} \\
\hline \multirow{2}{*}{\multicolumn{6}{|c|}{ 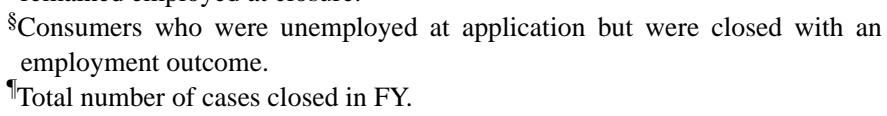 }} \\
\hline & & & & & \\
\hline \multicolumn{6}{|c|}{ Emp = employment, VR = vocational rehabilitation. } \\
\hline
\end{tabular}

a result, the data demonstrated that on average, consumers reported at the time of application in FY 1997 weekly earnings of \$125.92, increasing by FY 2007 to $\$ 206.05$, an increase of $\$ 80.13$. Hence, the difference in weekly earnings for consumers from the time of application to the time of closure was $\$ 167.17$ in FY 1997, yet the difference in FY 2007 was \$215.01, suggesting that earnings at closure had increased for consumers overall during this time period. Consumer weekly earnings at application and closure and their differences are found in Table 3.

\section{DISCUSSION AND CONCLUSIONS}

The rates of competitive employment for consumers of VR who are legally blind have been dismally low for decades, and hence, this study sought to determine whether this trend had begun to reverse. Clearly, the employment rate for consumers who are blind remains low and much more work needs to be done. Nevertheless, I find Cavenaugh's results promising [1]. The raw CCR for this population increased substantially from the 25.1 percent that Cavenaugh reported in 1999 [1] to 37.2 percent
Table 3.

Average weekly wages earned at application and closure for consumers who were legally blind ( $N=188,978$ ), fiscal years (FYs) 19972007.

\begin{tabular}{|c|c|c|c|c|}
\hline \multirow{2}{*}{ FY } & \multirow{2}{*}{$n^{*}$} & \multicolumn{2}{|c|}{ Wages (\$) } & \multirow{2}{*}{ Diff (\$) $)^{\S}$} \\
\hline & & $\mathbf{A}^{\dagger}$ & $\mathrm{C}^{\ddagger}$ & \\
\hline 1997 & 5,028 & 125.92 & 293.08 & 167.16 \\
\hline 1998 & 5,165 & 127.60 & 299.70 & 172.10 \\
\hline 1999 & 5,600 & 145.38 & 315.19 & 169.81 \\
\hline 2000 & 6,155 & 157.41 & 331.39 & 173.98 \\
\hline 2001 & 6,071 & 165.11 & 341.28 & 176.17 \\
\hline 2002 & 5,884 & 192.99 & 352.69 & 159.70 \\
\hline 2003 & 5,507 & 208.26 & 370.50 & 162.24 \\
\hline 2004 & 5,118 & 211.24 & 380.56 & 169.32 \\
\hline 2005 & 5,118 & 218.51 & 397.25 & 178.74 \\
\hline 2006 & 5,042 & 206.72 & 406.36 & 199.64 \\
\hline 2007 & 5,305 & 206.05 & 421.06 & 215.01 \\
\hline \multicolumn{5}{|c|}{$\begin{array}{l}\text { *Total number of consumers with competitive employment. } \\
{ }^{\dagger} \text { Mean wages at application (A). } \\
{ }^{\dagger} \text { Mean wages at closure (C). } \\
\S^{\$} \text { Difference (Diff) in earnings from anplication to }\end{array}$} \\
\hline
\end{tabular}

by FY 2007. Much of this trend was due to increasing trends of VR agencies opening cases on consumers who were already employed; yet, the rate of unemployed consumers who applied for services had continued to increase case closure in competitive work. While some fear that this trend was due in part to VR counselors putting consumers into any job that came along, a promising result is that the earnings of consumers had also increased along with the numbers finding work.

Data also demonstrated that an employment disparity continues to exist between men and women who are blind and that this trend had actually worsened over this period (1997-2007). These data demonstrate that men earned $\$ 0.63$ more an hour than women in 1997, and this increased by 2007 to an $\$ 0.86$ difference on average. Similarly, whereas the average spread between earnings (SD) was about $\$ 6.00$ in 1997 , the variability in earnings had increased to nearly $\$ 12$ for men but only $\$ 8$ for women. Also, over the 10-year period Native Americans had less employment in 1997 than the other racial groups, and remained substantially behind by 2007 . The same patterns remained constant in which Asian/Pacific Islanders earned the highest average wages and Black/African Americans earned the lowest average hourly rates. Additionally, the data showed that individuals who had earned a master's degree or higher by case closure had nearly a 40 percent greater chance of being employed and had $\$ 4.00$ an hour more in earnings than did individuals with less than a high 
school degree. Unfortunately, the data also demonstrated that American veterans are far underrepresented in the RSA-911 data system, and where they are identified, the rates of employment were a dismal 19 percent. Clearly, more focus needs to be placed on the factors that contribute to these data. Further research should also look at the employment outcomes for these populations because they are served in different geographic locations, within different states, and within different agency structures (i.e., specialized versus combined).

\section{ACKNOWLEDGMENTS}

Financial Disclosures: The author has declared that no competing interests exist.

Funding/Support: This material was unfunded at the time of manuscript preparation.

Institutional Review: This study was exempted by the Louisiana Tech University Institutional Review Board.

Participant Follow-Up: The author does not plan to inform participants of the publication of this article.

\section{REFERENCES}

1. Cavenaugh BS; Mississippi State Rehabilitation Research and Training Center on Blindness and Low Vision Mississippi State University. Relationship of agency structure and client characteristics to rehabilitation services and outcomes for consumers who are blind. Starkville (MS): Mississippi State University, Rehabilitation Research and Training Center on Blindness and Low Vision; 1999.

2. Capella ME. Predicting earnings of vocational rehabilitation clients with visual impairments. J Rehabil. 2001;67(4):43-48.

3. Bell EC. Comparing state vocational rehabilitation agencies with high versus low rates of competitive employment for blind consumers: Defining quality employment and describing effective service patterns [dissertation]. Fayetteville (AR): University of Arkansas, Fayetteville; 2004.

4. Bolton BF, Bellini JL, Brookings JB. Predicting client employment outcomes from personal history, functional limitations, and rehabilitation services. Rehabil Couns Bull. 2000;44(1):10-21. DOI:10.1177/003435520004400103
5. Hill MA. Work status outcomes of vocational rehabilitation clients who are blind or visually impaired. Rehabil Couns Bull. 1989;32(3):219-30.

6. Cavenaugh B, Pierce S. Characteristics, services, and outcomes of rehabilitation consumers who are blind or visually impaired served in separate and general agencies. Starkville (MS): Mississippi State University, Rehabilitation Research and Training Center on Blindness and Low Vision; 1998.

7. Bolton B, Neath J. Longitudinal stability and interrelationships of six criteria of rehabilitation counselor performance. Rehabil Couns Bull. 1995;39(1):15-24.

8. Cook DW, Bolton B. Rehabilitation counselor education and case performance: An independent replication. Rehabil Couns Bull. 1992;36(1):37-43.

9. Szymanski EM, Parker RM. Relationship of rehabilitation client outcome to level of rehabilitation counselor education. J Rehabil. 1989;55(4):32-36.

10. Mullins J, Roessler R. Improving employment outcomes through quality rehabilitation counseling (QRC). J Rehabil. 1997;63(4):21-32.

11. Rumrill PD Jr, Roessler RT. New directions in vocational rehabilitation: A "career development" perspective on “closure.” J Rehabil. 1999;65:26-31.

12. Schroeder F. Changing patterns in the rehabilitation system: Meeting the needs of the blind and otherwise disabled. Braille Monit [Internet]. 2000 [cited 2010 Feb 8];43(8). Available from:

http://www.nfb.org/legacy/bm/bm00/bm0008/ bm000805.htm/.

13. Kirchner C, Schmeidler E. Prevalence and employment of people in the United States who are blind or visually impaired. J Vis Impair Blind. 1997;91:508-11.

14. Szymanski EM, Parker RM, Butler AJ. Sensitivity of client outcome measures in relating state vocational rehabilitation agency counselor performance to level of counselor education. J Rehabil. 1990;4:93-107.

15. Rehabilitation Services Administration. Evaluation standards and performance indicators for the Vocational Rehabilitation Program [Internet]. Washington (DC): U.S. Department of Education; 2008 [updated 2009 Jun 29; cited 2008 Dec 7]. Available from: http://www.ed.gov/rschstat/eval/rehab/standards.html/.

Submitted for publication August 11, 2009. Accepted in revised form December 22, 2009. 
